\title{
Trayectoria intelectual y política de Roberto Campos desde su narrativa del yo
}

\author{
Intellectual and political trajectory of Roberto Campos from narrative of self \\ Trajetória intelectual e política de Roberto Campos desde sua escrita de si
}

Hernán Ramirez ${ }^{*}$

\section{Resumen}

A partir de la narrativa del yo, en el presente artículo, indagamos sobre el giro experimentado en el pensamiento y la acción pública de Roberto Campos, figura clave de la política económica brasileña en la última mitad del siglo pasado, en cuyo recorrido se deslizó desde posiciones próximas al Estructuralismo en su juventud para abrazar la variante más ortodoxa del Neoliberalismo más adelante, de modo militante. Al explicar las razones de esa transmutación, observamos que su trayectoria no fue solo una muestra individual, sino que ilustra, con sus matices particulares, los derroteros que siguieron en la región el campo de la economía de modo general, el de las políticas públicas y otras personalidades en particular, que también trazaron un curso semejante y pueden entenderse mejor a la luz de esta.

Palabras clave: Acción política. Brasil. Narrativa del yo. Pensamiento económico. Roberto Campos.
[...] Lutei contra as marés do nacional-populismo, antecipando o refluxo da onda. Às vezes ousei

profetizar, não por ver mais que os outros, mas por ver antes. Por muito tempo, ao defender o liberalismo econômico, fui considerado um herege imprudente. Os acontecimentos mundiais, na visão de alguns, me promoveram a profeta responsável. Roberto Campos ${ }^{1}$

\section{Introducción}

Cuando analizamos trayectorias de vidas caben dos alternativas que podemos indicar como polos opuestos: estas pueden representar eventos singulares, únicos $\mathrm{e}$

Doutor em História pela Universidade Federal do Rio Grande do Sul, Brasil. Com pós-doutoramento no Instituto Universitário de Pesquisas do Rio de Janeiro, Brasil. Professor na Universidade do Vale do Rio dos Sinos, Brasil. E-mail: hramirez1967@ yahoo.com

Recebido em 11/04/2016 - Aprovado em 15/12/2016

http://dx.doi.org/10.5335/hdtv.17n.1.6501 
irrepetibles, de figuras que descuellan en su época, o enmarcarse como ejemplos de los caminos que siguen conjuntos más amplios de individuos, que trillan caminos de modo más o menos similar. Si bien su transmutación fue particular, y por momentos puede parecernos aparentemente desconcertante, procuraremos recorrer en este artículo los pasos de Roberto de Oliveira Campos, uno de los personajes que marcó la economía brasileña de la última mitad del siglo XX, no solo como ministro do Planejamento, del gobierno del general Castelo Branco, durante la dictadura cívico militar instaurada tras el golpe de Estado de 1964, que fue su paso más conocido, sino en sus periodos previos, como funcionario de los gobiernos de Vargas y Kubitschek, a los que sirvió en importantes puestos, y posteriores, cuando tuvo expresión política de nota y se abocó fundamentalmente a la propagación del ideario neoliberal, desde el Parlamento y como figura pública de la Nueva República.

Vemos así que su historia de vida se entrelaza con diversos momentos de la historia nacional de su país, manteniéndose en el tapete durante todo ese extenso periodo, en el cual como malabarista supo equilibrarse por hitos que expresan quiebres abruptos, en los cuales pasó de profesar posiciones rayanas con el Estructuralismo a otras abiertamente Ortodoxas, en las antípodas de aquellas, lo que, en última instancia, nos muestra también cuáles fueron las ideologías dominantes de cada uno de esos extremos del recorte temporal abarcado por la trayectoria de Campos, que dejó una obra proficua en número de textos escritos, uno de corte au- tobiográfico, el cual nos servirá de lazarillo heurístico.

En particular nos hemos detenido en una obra específica de Campos, su narrativa autobiográfica, que tiene ribetes nada habituales en otras del género, dado que no sigue recortes cronológicos ni temáticos sistemáticos, sino que se desliza aleatoriamente en una caótica sinfonía, elección difícil de racionalizar en motivos, pero que a toda hora deja indicios preciosos que pueden auxiliarnos en la interpretación de su extensa trayectoria.

Obras de ese género nos muestran la representaciones del curso vital, así como sirven para constatar otras características que se presentan a modo de síntomas epocales, no necesariamente conscientes en las narrativas del yo, que, como muchas veces se alerta, en personalidades del tipo tiene el propósito de ordenar lo que en principio no parecería ser tan claro, a la vez que con ello también se agigantan eventos que de otra forma podrían parecer triviales o se escamotean otros menos abonadores, funcionando de esa manera como una guía póstuma para su epitafio.

Si bien el relato de Campos se aleja de los modelos lineales (HOFSTADTER; DENNETT, 1981-1983, p. 348-352), al no seguir un orden cronológico, comparte con las narrativas del yo el hecho de ser una autodefensa de su obra, autobiografía que ha sido construía por una conciencia moldada históricamente, la que, a su modo, deja trasparecer tanto sus componentes personales como muchos colectivos.

Usamos el colofón del prefacio de su autobiografía como norte, que es bastante 
sintomático en varios aspectos y da sentido a su título, en el cual Campos se vale de Samuel Taylor Coleridge, para quien "a luz que a experiencia nos dá é a de uma lanterna na popa, que ilumina apenas as ondas que deixamos para trás" (1994 apud CAMPOS, 2001, p. 22).

Por ello, la propuesta que hacemos es la de tratar de entender esas olas que Campos dejó tras de sí, la que se explican en virtud de muchos factores y las que a su vez nos pueden ser útiles para entenderlos también. En tal sentido, para arrancar en tal interpretación, nos valemos de Martyn Hammersley (1994), quien rechaza toda posibilidad de aislar un conjunto claro de supuestos paradigmáticos y alega que solo existe un continuum epistemológico, donde cada investigación particular invoca sus propios principios epistémicos.

Así, como hipótesis amplia, compartimos la idea de que las teorías se sitúan en una línea más o menos extensa de posiciones, y no todas se disponen en ella de igual modo, incluso porque algunas pueden extenderse por un espectro muy extenso de ellas, como de hecho acontece con el Estructuralismo y el Neoliberalismo, que han sido apropiados por individuos en posiciones bastante distantes entre sí, a la vez que han sufrido deslices temporales muy marcados, a medida que se construyeron y resignificaron, lo que a la postre dificulta las categorizaciones que podamos realizar, lo que para mayor complejidad puede acontecer hasta en las propias trayectorias de los actores sociales, ya que a menudo es posible observar variaciones bastante considerables en las posiciones asumidas durante toda una vida, como de hecho ocurrió en el caso de Campos.

De este modo, usando esta interpretación dinámica de la constitución de las teorías, podemos explicar mejor los propios vaivenes en el pensamiento y la acción política de Roberto Campos, debido a que él mismo aparenta haber seguido esta misma lógica. Así, en panorámicas estáticas, nuestro protagonista de los orígenes parece muy distante de la figura que se consagró posteriormente, lo que encuentra una explicación mucho más plausible como un lento proceso, en el cual fue madurando su metamorfosis, la cual analizaremos a continuación, buscando en toda su trayectoria, no solo intelectual sino también personal, así como en las coyunturas por las cuales atraviesa, claves que nos ayuden a descifrarla.

\section{Remar contra los orígenes}

Nacido en un seno familiar relativamente modesto, a pesar de los esfuerzos por ennoblecerlo realizados en su autobiografía (CAMPOS, 2001, p. 127-133), de padre paulista, inspector de escuelas, y madre matogrosense, tuvo una existencia errática hasta su consolidación. Ante la desaparición prematura de la figura paterna, su progenitora, perteneciente a un extenso linaje, buscó refugio en una de las propiedades familiares, que tiempo después abandonó para obtener su propio sustento como modista y así dejar de vivir de favores. $Y$, con futuro incierto, Campos buscó a través de la Iglesia, como tantos otros, un medio de ascender socialmente, cursando Filosofía y Teología (2001, p. 135-142). 
"O padreco, filho de costureira" es el subtítulo que escoge Campos para uno de los apartados de su autobiografía (2001, p. 135), en el cual comenta esos pasajes de su saga, sonsonete que denota una visión de menosprecio, aunque algo encubierto por su sarcasmo, que se tenía sobre tales condiciones, y que a su medida afloran en varios momentos.

De todas formas, dichas condiciones no fueron escollos que inhibieran vuelos más altos. Manifestando cierto utilitarismo, escribe:

Ia à Igreja e seduzia-me a aura mística e a opulência da liturgia. Resolvi entrar no seminário e seguir a carreira do sacerdócio. Havia uma consideração prática importante. O seminário era uma excelente escola e, além do mais, gratuita. Minha consideração, entretanto, era mais mística que pragmática. Acreditava-me tocado pela vocação (CAMPOS, 2001, p. 136).

No obstante, sin entrar a cuestionar su genuina llamada, abandonó la carrera sacerdotal antes de profesar votos superiores. Viéndose sin futuro a la vista, se dedicó a la docencia, que en Brasil es muy mal remunerada hasta los días actuales, salvo excepciones. Por lo cual pasaría a tentar suerte en la función pública. Primero prestó concurso como escriturario, pero fue reprobado por no saber dactilografía, y después como inspector de escuelas, tal vez emulando los pasos paternos, pero no obtuvo el reconocimiento de sus diplomas, lo que lo lleva a autocalificarse como un "analfabeto erudito", mote que escoge como parte inicial del título de su primer capítulo, lo que repetirá más adelante (CAMPOS, 2001, p. 25, 141).
Estos tropiezos iniciales no serían obstáculos suficientes para desestimular al determinado Campos, quien hallaría en la carrera diplomática su destino, paradójicamente una posición mucho más encumbrada que las intentadas antes, que no por casualidad decide situar como puntapié inicial de su floreada autobiografía.

Nos permitimos abrir aquí un extenso paréntesis para explicar algunas características de la burocracia brasileña, que son importantes para comprender el desarrollo del ethos de Campos, el éxito en sus pasos futuros y algunas características de su comportamiento social, político e intelectual.

Desde tiempos anteriores al Imperio, la administración pública es un importante medio de ascenso social, y algunos de sus aparatos constituyen reductos selectos, en particular el servicio diplomático, al que se llega por méritos demostrados en concurso, que requieren sólida formación previa, que pocos pueden alcanzar, por lo que en su mayoría son componentes de la élite. Esos orígenes, así como la estabilidad, justamente en un período de quiebres abruptos, y el roce internacional que suministra, que en estas regiones se tiene en gran aprecio, confieren a sus integrantes un espíritu de cuerpo y empoderamiento individual sumamente particular, los que se sienten auténticos aristócratas, lo que nuestro objeto de estudio deja entrever con fruición en varios pasajes de su autobiografía, en particular cuando narra su estancia en la Corte de Saint James y los grandes personajes que llegó a conocer, en especial cuando comenta en detalle las ceremonias que involucraban sus encuentros protocolares y de visitas con el jefe del 
Estado brasileño a la Reina (CAMPOS, 2001, p. 935-936, 973-976).

En ese relato tenemos la sensación de que lo más importante para su ser ha estado en haber presenciado momentos cumbres de la historia mundial, codeándose con personajes eminentes de los centros de poder, a los cuales ingresó, como muchos eventos de su vida, de modo azaroso, si confiamos en su relato, y tuvo que batallar intensamente para ser admitido como par.

Tal expresión no es una mera enunciación retórica, sino que tiene indicadores empíricos palpables, generales y particulares. En el apartado homónimo, Campos se sitúa entre los "patinhos feios" (2001, p. 33-34) del grupo, junto a otro compañero, marcando claras desventajas de origen. "Mas o mais grave é que nós dois não conhecíamos ninguém no Itamaraty, enquanto o restante dos colegas ou eram repetentes de concursos ou tinham ligações de parentesco ou amizade com o pessoal da casa" (2001, p. 33-34). Relaciones que le permitieron destinos más prometedores:

Foram todos eles assim requisitados para os diferentes departamentos mais nobres [término que también denota resabios de tiempos coloniales e imperiales en el discurso cotidiano brasileño] - o Político, Jurídico e o Cultural. Não tendo sido nossos trabalhos requestados por ninguém, fomos consignados à Divisão de Material, ou seja ao almoxarifado (2001, p. 33-34).

Para escapar de él, se inscribió en la Sección de Criptografía, trabajando junto a otros intensamente en códigos diccionarios durante la Segunda Guerra Mundial. Al final de la faena, la modesta recompensa fueron sus entregas secretas en diversas plazas, en lo cual fue nuevamente postergado, cabiéndole la misión de hacerlo en Montevideo, Buenos Aires y Asunción, correspondiendo a otros los mejores destinos, en Europa y Estados Unidos.

Ao regressar ao Itamaraty, acalentava a esperança de ser afinal transferido a uma das divisões mais nobres e condizentes com meu treinamento humanístico. Fui novamente consignado a uma divisão desprestigiosa - a Divisão Comercial -, então apelidada de secos e molhados (2001, p. 40).

Algo que puede ser traducido como "almacén general" o en traducción más libre, pero tal vez más acertada, como menudencias. De nuevo volvía casi al punto de partida. No era fácil ascender y Campos ya lo sabía.

“O Itamaraty [...] era comumente apelidado de Butantã da Rua Larga. - São cobras [víboras], mas fingem que são minhocas [lombrices] - dizia-me dos seus colegas o admirável Guimarães Rosa, que depois se tornaria meu escritor preferido" (CAMPOS, 2001, p. 31). Y, de hecho, una sentencia suya fue escogida como segundo epígrafe, entre tres, de su obra autobiográfica. De todos modos, tal vez la descripción de Campos sea algo injusta con su sitio de trabajo, ya que la metáfora no le es privativa, pudiéndose decir que es otra característica de la práctica social local, basada en un habitus de corte, construido en la época colonial y durante el Imperio, que se ha preservado en la vida republicana, en el que las rivalidades no son puestas de manifiesto públicamente, sino encubiertas por una fachada cordial.

De todos modos, la rueda de la vida le brindaría una nueva oportunidad, cuan- 
do el Itamaraty lo convocó a su primer gran destino: Estados Unidos. Una vez allí, por su origen humilde y formación algo sui generis, nuevamente fue a parar a un destino poco importante, recalando en nuestro conocido "almacén general". En sus jocosas palabras, "Lá me vi metido de novo nos secos e molhados, redigindo pedidos de autorização para fabricação, exportação, praça marítima e quotas de petróleo".

\section{Embarcarse en la economía}

Sin resignarse a un triste final, fue en este arcón de despojos donde decidió abrazar, hasta cierto punto, la economía como su tabla de salvación. "Conclui ser inútil pelejar contra o destino. Decidi-me a estudar economia nos cursos noturnos da George Washington University" (CAMPOS, 2001, p. 48), hecho que pinta de modo más crudo en el capítulo "Economista sobre protesto", donde expresa:

O Destino se compraz em pregar peças, favoráveis ou desfavoráveis, aos pobres mortais. Fora sob protesto que eu me vira consignado, no início de minha carreira no Itamaraty, à Divisão de secos e molhados. Foi também sob protesto íntimo que me decidi a passar das letras clássicas ao estudo da economia, em Washington e Nova York, estudando à noite após longa faina burocrática (CAMPOS, 2001, p. 53).

Así, la Economía no era su Meca, sino un instrumento más para progresar en los disputados y aparentemente peligrosos pasillos del Palacio, un interludio, como reza uno de los apartados de su obra (CAMPOS, 2001, p 77-79). Fue en aquella universidad donde obtuvo su maestría, único diploma que conquistó en el área económica, ya que posteriormente intentaría un doctorado en la Universidad de Columbia, que no concluyó, tal vez porque no era de su interés o capacidad, aunque como autojustificación lo asocia a la fortuna: "Edward Acheson [deán de la School of government de la George Washington University] era uma figura bizarra. Economista não por vocação e sim por resignação, destino semelhante ao meu" (CAMPOS, 2001, p. 48). Comparación que más adelante retoma comentando pasajes de la vida del hermano de aquel:

Curiosamente, Acheson [Dean], advogado eminente, tinha experimentado, no Departamento de Estado, ao ser designado para o setor econômico, a mesma frustração que eu, como modesto principiante, experimentara [...] frustradamente, para o grande causídico, coube-lhe o setor econômico, que era então considerado menos expressivo. Era uma atividade, como diz Acheson, "debaixo da escada" algo semelhante aos secos e molhados do Itamaraty (CAMPOS, 2001, p. 53-54, itálicas en el original).

En ese cotejo podemos ver que lo azaroso de la carrera académica de Campos no era un caso estrictamente individual, y sí una muestra clara del panorama presente en las ciencias económicas como campo de estudios en la región toda, y Brasil mucho más aún, que no tenían campo consolidado. Además del triste caso de Acheson, la mayoría de los "economistas" del periodo siguieron trayectorias más o menos parecidas. Muchos de ellos provenían de otras áreas y se dedicaron a su estudio en un estadio posterior, varias veces conducidos por otras necesidades, y, ya en la nave, el salto se dio en cursos de posgrado realizados en el exterior. 
Como un botón sirve de muestra, hemos escogido la carrera de Celso Furtado, quizás el economista más reconocido de Brasil, para ofrecer otro ejemplo que lo avale, ya que su carrera tuvo un curso básicamente similar en sus inicios. Graduado en Derecho en la Universidad de Río de Janeiro, fue convocado por la Força Expedicionária Brasileira para servir en Italia en los estertores de la Segunda Guerra Mundial. Ya en Europa, ingresó al doctorado en Economía de la Sorbonne, en 1946, que terminó dos años después, para instalarse en Chile en 1949, donde integró la recién creada Comisión Económica para América Latina (Cepal).

De todos modos, a diferencia de Furtado, Campos no tuvo papel protagónico como teórico sino más bien como "espectador comprometido" (CAMPOS, 2001, p. 80) o propagandista, agitador en las alturas, lo cual recuerda con cierto amargor al enunciar en el prólogo las intencionalidades de su autobiografía

Conto neste livro as peripécias do menino do Pantanal, que se tornou teólogo no claustro, diplomata na guerra e na paz, economista presente à criação da arquitetura econômica do pós-guerra, passando depois a tecnocrata, administrador e político[...] Em nenhum momento consegui a grandeza. Em todos os momentos procurei escapar da mediocridade. Fui um pouco um apóstolo, sem a coragem de ser mártir (CAMPOS, 2001, p. 20).

Rematando: "Nunca tive profundidade, inteligência ou poder para erguer um farol que lançasse um facho de luz para as futuras gerações. Estas memórias são apenas uma lanterna na Popa de um pequeno barco..." (2001, p. 22).
Más que una manifestación de modestia, incongruente en él, que se exhibe a todo momento, el texto es pletórico en pasajes que muestran cabalmente esa frustración intelectual. Hablando de su tesis de maestría, se queja de que:

Ambos [Nurske e Viner] me declararon que a tese continha percepções inovadoras que mereciam destino melhor do que um arquivo universitário. Sentia-me, entretanto, assaz inibido e talvez excessivamente tímido, quer em relação ao meu etilo, quer à minha originalidade em termos de pensamento econômico (CAMPOS, 2001, p. 77).

De hecho, Campos tuvo una ecléctica influencia y un curso azaroso, posicionándose en un campo claro tardíamente. En los escuetos pasajes en los que discurre sobre sus influencias teóricas, expresa:

Assisti a cursos de todos eles e depois, por intermédio de Eugênio Gudin, tornei-me amigo pessoal de dois deles: Gottfried Haberler e Fritz Machlup. Eram todos perseguidos do nazismo e pertenciam àquilo que os alunos, com afetuosa ironia, descreviam como a máfia austríaca (CAMPOS, 2001, p. 49).

Más adelante hace una importante reserva,

Um dos meus ídolos intelectuais da época era Joseph Alois Schumpeter, que lecionava em Harvard..., correspondi-me com Schumpeter [que dice haber procurado para ser su director de tesis de su frustado doctorado en Columbia] [...] Entretanto, as lições dos visitantes austríacos na George Washington eram apenas um interlúdio de ideias liberais. O que estava em voga era o keynesianismo (CAMPOS, 2001, p. 50-54). 
En entrevista posterior, declaró que Haberler y Nurkse, ambos de la Universidade George Washington, fueron los profesores más importantes que tuvo. No obstante, Eugênio Gudin habría sido, según sus palabras, quien más lo influyó en su formación profesional, a través de su libro Princípios de Economia Monetária.

Más específicamente, la inspiración de su tesis de maestría estaba en las "teorías sobre los ciclos económicos, servindo-me principalmente dos trabalhos seminais de Schumpeter e também de Wesley C. Mitchell" (CAMPOS, 2001, p. 77). La cual "Continha também um estudo sobre Lord Keynes e a teoria do imperialismo" (CAMPOS, 2001, p. 77).

Como se puede apreciar, la figura de Roberto Campos se va moviendo en ese continuum epistémico del cual Hammersley (1994) nos habla. En él, las circunstancias desempeñan un papel significativo, pero los actores no juegan libremente, sino que se deslizan sobre un entramado estructural que les da sustento. Por ello, las transformaciones en el propio campo de la economía, como ciencia y objeto de disputas políticas, también pueden haber desempeñado un papel importante en las transfiguraciones que experimentaron los pensamientos de determinados actores, en general, y el de Roberto Campos, en particular, que tuvo necesidades de adecuarse a ese contexto, dada su profesión, sus aspiraciones dentro de ella y sus limitaciones, personales y estructurales.

Las cosmovisiones funcionan como una especie de marco en el cual nuestros pensamientos se posicionan, y no es de extrañar que muchos los adecuen no solo por convicciones genuinas, sino para no desentonar con el espíritu que domina en determinados espacios y épocas, lo que actúa como un poderoso motor o inhibidor de cambios, incluso porque en ellos se juegan diversos intereses, además de galardones.

Por ejemplo, las ideas dominantes que inspiraban los economistas, por formación u opción, oscilaron de ese continuum del cual hablábamos, desde posiciones keynesianas y estructuralistas a mediados de siglo hasta otras que adhirieron con fervor a nociones ortodoxas, ya a partir de la década de setenta, y se tornaron hegemónicas en los ochenta y noventa. Aunque hay que advertir que en Brasil esa adhesión fue menor a la que se registró en países vecinos como Chile y $\mathrm{Ar}$ gentina, por ejemplo.

Ese fue un cambio de registro que operaba en múltiples esferas, y no solo se reducía a lo eidético. Las instituciones multilaterales, por ejemplo, en las cuales Campos había convivido desde su nacimiento, habían estado enroladas en vertientes estructuralistas primeramente, pero después fueron barridas por otros vientos, que diezmaron, literal y figuradamente, de sus cuadros aquellos que las profesaban, cuyas estructuras fueron colonizadas de modo encarnizado en muchos casos por vertientes ortodoxas, algunos conversos de última hora, como profundizaremos más adelante

Por ello es importante comprenderlas para entender mejor determinados cursos que se siguen, con lo que abrimos otro gran paréntesis para elucidarlo mejor. Al tratar de entender cómo surge el interés, Hirschman (1999) observa que existen explicaciones de naturaleza económica en la aversión 
al cambio. Su hipótesis trata de establecer un nexo entre las inversiones realizadas por los sujetos y la propensión a realizar vuelcos radicales en sus vidas, observando que tales variables serían inversamente proporcionales, es decir, mientras más gastos en esfuerzos y recursos hayan sido realizados, habría más interés en mantener el estado anterior, rechazando cualquier mudanza que ponga en riesgo lo conquistado. Contrariamente, si existen perspectivas y garantías de mayores remuneraciones ante el hecho de efectuar conversiones o ver amenazadas las inversiones realizadas por mantenerse en sus posiciones, los agentes tendrían mayores estímulos para realizar esa reconversión.

Con ello interpretamos mejor las vicisitudes de las posiciones teóricas de Campos, que estuvieron influenciadas por la ola en boga. Una vez pasada la primera, un aficionado de las artes de navegar como él, refluyó con la marea. No obstante, volviendo al argumento central de este artículo, el flujo que ese proceso siguió no fue tan claro, ni sincrónica ni diacrónicamente, registrándose un panorama sumamente complejo.

En este sentido, valiéndonos nuevamente de la tesis de Hammersley, podemos asemejar al Keynesianismo, Estructuralismo y Neoliberalismo con grandes constelaciones (BALSA, 2007) que se fueron amalgamando en un movimiento que recibió aportes de una serie de actores que tenían como propósito entender o solucionar determinados problemas, ya sea a través de la teorización o la práctica política. Por ello no hay uniformidad, incluso la idea de consenso neoliberal ha sido desterrada actualmente (PLEHWE, 2011). De esta forma, las zonas nebulosas abundan, y si bien se imponen determinados catecismos, o algunos astros parecen brillar más que otros, atrayendo por su campo gravitacional varios menores que los secundan, no ha existido una convergencia monolítica, salvo en algunas circunstancias en que tales conceptos conseguían establecerse hegemónicamente, cuajando allí una idea teorética que posteriormente se asocia a dichos conceptos.

Ex profeso, hemos preferido el término Estructuralismo, ya que muchas otras teorías han tratado del Desarrollo, aunque haya sido una que se apropió del nombre, tal vez por centrar en ella sus principales debates y contribuciones. Igualmente, bajo el término Neoliberal se ha subsumido toda una serie de linajes con procesos más o menos autónomos, aunque con diversos vasos comunicantes; incluso, tal corriente posee sus propias concepciones respecto del desarrollo. En este sentido, vemos el neoliberalismo de modo más extenso que lo propuesto por Harvey (2008), quien admite solo las matrices anglosajonas en su constitución, pero en el cual también se pueden reconocer otros aportes, entre los que se cuentan fundamentalmente el Ordoliberalismo, las escuelas Austríaca, de Chicago y de Virginia, o de la Elección Pública.

Extensas son las discusiones sobre el origen y curso de ellas, entabladas desde perspectivas y recortes diversos. No obstante, entre las opciones disponibles somos partidarios de escoger una visión amplia de la forma como ellas se compusieron, ya sea en su consideración en el campo de las ideas, o su conexión con el tejido social, que las posibilita y nutre, que les marca caminos y 
límites, ya que, igualmente, nuestra opción es verlas de modo complejo. De hecho, no fueron ideas restrictas a lo académico, sino cosmovisiones que ayudaron a construir el mundo, funcionando como ideologías acerca del modo en que debía estructurarse y actuar el sistema capitalista.

Por ello, hemos obviado intencionalmente de tratarlo como mero contexto, porque la palabra da la sensación que se trata de un caparazón que envuelve el objeto, pero tal relación es mucho más activa, dado que los dos se imbrican de tal forma que se tornan indisociables. De todos modos, somos conscientes de las necesidades analíticas que nos obligan a discernirlos separadamente, lo que nos lleva a establecer algunas analogías que sirvan a modo de desencadenadores para pensar esa construcción dialéctica.

Asimismo, nos parece que nuestras hipótesis hasta aquí expuestas se encuentran parcialmente incompletas si no se asocian a otras, que las complementan y amplían, en especial para explicar giros radicales en determinados pensamientos, siendo más fácil encontrar explicaciones en el deslizamiento entre matices, y no hacia posiciones más alejadas dentro de ese continuum teórico. Por ello, adoptar el concepto zona de desarrollo próximo, empleado por Vigotsky y muy usual en pedagogía, puede brindarnos un insight que nos posibilita pensar esos cursos, no desde posiciones cerradas in totum, sino mediante el paso por una zona intermediaria, que conjugaría elementos de los dos universos, lo que tornaría admisible la nueva teoría, que en otra circunstancia aparecería muy distante, poco conciliable con sus propias experiencias anteriores, hecho difícil de justificar ante sí y los otros, incluso en un campo donde esos procesos cumplen papel expresivo, no solo dentro de los marcos estrictamente teóricos, sino también por otros meandros que también son significativos, como los de la propia supervivencia y el ascenso individual, como bien apuntan muchos trabajos de Bourdieu, con costos de reconversión más o menos directamente proporcionales al salto que se pretende dar. Resultado que puede alterarse si se modifican algunas de las premisas iniciales.

Por ello hemos remarcado mucho el contexto que Campos vivió, con el claro dominio del Keynesianismo, construido para entender y controlar los ciclos; la emergencia del Estructuralismo, que pretendía contestar y revertir la dependencia regional; y la supervivencia del Liberalismo clásico casi a hurtadillas, renovándose mucho más adelante bajo el prefijo Neo, el que en feroz combate se impondría, mundo afuera y adentro de las fronteras nacionales, como ideología hegemónica de la reestructuración posfordista del capitalismo (RAMÍREZ, 2013).

Esto no se reducía a debates de iniciados, sino que era el caldo de la lucha política, lo que nos ayuda a entender algunos de sus más importantes virajes históricos. La descomposición del Estructuralismo, como bien señaló Bielschowsky (1995), no se debía exclusivamente a cuestiones teoréticas, sino que refleja otras tensiones que lo excedían. En esencia, la reyerta que planteaba apuntaba más alto que sofisticadas cuestiones académicas. Al amenazar el propio statu quo, ya que en última instancia ponía en tela de juicio el pacto neocolonial y de dominación existente, sólidamente enraizado, proponía 
como solución un problema mayor. De ese modo, aquellos partidarios de visiones más moderadas tendieron a desplazarse hacia posiciones más conservadoras a medida que el conflicto se amplificaba, pasando a abrazar otros tipos de soluciones menos drásticas.

Incluso, este cambio abrupto en las preferencias teóricas no ocurrió solo por una súbita reorientación del viento dentro de claustros, espacios académicos y otros entes que congregan las experticias económicas, sino que muchas veces se dio mediante una fuerte acción disciplinadora dentro y desde esos órganos, que pasó a ser ejercida en modo jerárquico desde el Banco Mundial/ Banco Internacional de Reconstrucción y Fomento, reducto de los usamericanos y del Fondo Monetario Internacional, tercerizado a los europeos, que rediseñó el entramado mundial capitalista tras Bretton Woods (SKLAR, 1980; COATS, 1986; SMITH, 1991; OVERBEEK, 1993; CORBALÁN, 2002; y PLEHWE, 2007).

Destacamos el término disciplinarización, ya que de hecho se produjo un agresivo combate contra otros tipos de concepciones teóricas mediante toda una serie de subterfugios, principalmente al cerrarles las puertas a créditos blandos o el apoyo a inversiones directas a aquellos gobiernos que no comulgaban con sus posiciones, o al colocar en peligro o en marcha lenta las carreras de técnicos que las contrariaban o no se sometían dócilmente. Incluso, en muchos casos, dichos combates tuvieron ribetes más duros y hasta trágicos, llevando al exilio y hasta la muerte a muchos economistas que no se ajustaban a tales designios ${ }^{2}$.
Como ideología, el Neoliberalismo se basó también en muchas de esas estrategias para imponerse. A pesar de hacer referencia a un concepto anterior que se asocia a las palabras libertad, trae implícita una contradicción, paradoja, según Kahler (1989), después retomada por Evans (1992), ya que muchas veces se ha contrapuesto a ella, asociándose a regímenes autoritarios que reprimen garantías individuales y colectivas, y que también aplican el más férreo proteccionismo y usufructúan la ayuda estatal cuando les interesa, dejando para los otros el librecambio y la acción de la mano invisible del mercado.

Esto se debe en esencia a la confusión ontológica del concepto Liberalismo, ya que puede hacer alusión tanto a la esfera política como económica, lo que muchas veces se mantiene ex profeso, con la intención de apropiarse indebidamente de una tradición cara al pensamiento y la acción políticos. No obstante el prefijo neo, usado en la composición de la nueva teoría, no importa in totum aquella otra, ni la tendría como base, ya que en esencia este se formuló como crítica a aquel, al que juzgaba haberse rendido al Keynesianismo, y lo veía presa fácil del comunismo.

Retornando al ejemplo de Furtado, no resulta extraño que su carrera como economista no se haya valido de las credenciales de alguna institución educativa usamericana, lo que muestra en esencia un distanciamiento de Campos, que buscó en ella un refuerzo simbólico para congraciarse con el establishment, como también lo harían muchos otros, ya que el tránsito por ellas pasó a ser casi una condición sine qua non para asu- 
mir posiciones más encumbradas. Por otro lado, no deja también de ser sintomático que, mientras Campos subía al Ministerio, Furtado perdía sus derechos políticos y marchaba al exilio, como prueba de lo comentado en nuestra única cita al pie.

\section{Llegara la proa}

Por ello, no es de extrañar que el periodo en que se produjo este cambio en las orientaciones de política económica y el pensamiento dominante coincida con la instauración de regímenes autoritarios que barrieron del horizonte no solo corrientes vinculadas a posiciones de izquierda, sino también otras más moderadas, que le hacían frente, muchas veces de modo contundente, dado que sus intenciones no eran meramente represivas sino refundacionales, estando en la economía la clave de esa rearticulación.

Igualmente hay que considerar, para entender mejor la participación en una administración autoritaria por parte de nuestro personaje que se dice liberal, que dichas administraciones no tenían el fuerte rancio de desprecio de la actualidad, a la par que eran aprobadas por diversos actores, internos y externos, que también conformaban parte de su referencial.

Paradójicamente, los golpes de Estado fueron detonados para proteger la democracia, que, según el discurso de la época, creían en peligro. De hecho, ninguna de las dictaduras del Cono Sur se pensaba como una solución totalitaria, aunque hubiera corrientes, con mayor o menor poder de fuego, que así lo propusieran. Todas ellas se veían como una solución de facto que, en un tiempo prudencial, luego de conseguir los objetivos deseados, devolverían el poder ya saneado a autoridades electas por el poder del voto. Incluso, en el caso brasileño hubo elecciones más o menos regulares y, hasta cierto punto, competitivas, a las par que se preservaron algunas instituciones $o$ se pretendieron crear otras donde pudiera ser expresada la manifestación de divergencias, aunque fuertemente condicionadas. Lo que bajo ningún punto de vista podemos considerar como un mero simulacro de dar barniz pseudodemocrático a estos gobiernos, sino que tal estrategia estaba en sintonía con las metas de largo plazo que pretendían, las que incluían el preparar grupos políticos defensores del statu quo que pudieran disputar el poder de modo más competitivo a lo que lo habían hecho antaño, cuando eran incapaces de conseguir el poder por medio de la voluntad popular (LINZ, 1978), a la vez que disminuir el poder de los grupos que pudiesen cuestionárselo, incluidos allí los intelectuales, estructuralistas en particular.

Las dictaduras tuvieron objetivos refundacionales explícitos, como nos muestra el Ato Institucional n. I en Brasil, cuyo golpe de Estado se auto intituló una Revolución, nomenclatura que también usaron varios putschs en Argentina hasta el de 1976, que lo abandonó para denominarse pomposamente Proceso de Reorganización Nacional, con lo cual dejaba en claro cuáles eran sus propósitos (GARRETÓN, 1984; SIDICARO, 1996; RAMÍREZ, 2014; y RAMÍREZ , 2015).

En ese sentido, tal vez, el ejemplo brasileño, junto con el chileno, sea el que mejores 
resultados tuvo en implementar reformas de acuerdo con los objetivos previstos, ya que, después de un breve pas de deux bipartidista protegido y limitado, las fuerzas más radicales fueron aniquiladas, a la vez que el centro fue ganando la escena. Por su parte, el nacional-populismo de raíz varguista salió del proceso con menos peso, y ninguna fuerza partidaria anterior al golpe de Estado de 1964 se alzó con el poder, siendo todas ellas frutos posteriores, el que quedó profundamente fragmentado.

En palabras del propio Campos:

Para Castello, do outro lado, era objetivo prioritário marcar a diferença entre a Revolução brasileira e uma quartelada ditatorial sul-americana. A imagem externa do país exigia um mínimo de continuidade nas formas constitucionais. Internamente, a cirurgia deveria ser confinada aos casos incontestes de subversão e corrupção. A demagogia e o clientelismo, tão grande e corretamente estigmatizados pelo Estadão [se refiere al periódico Estado de S. Paulo], tinham que ser curados por uma lenta reconstrução do tecido político, através de uma reeducação da classe política e não por um processo de cauterização (2001, p. 791).

Así podemos entender mejor las razones que llevaron a las fuerzas dictatoriales a darle a Campos un ministerio estratégico como el de Planejamento, para lo cual podemos ensayar una respuesta aún más compleja. En varios pasajes de su obra, Campos se autodefine como un tecnócrata, es decir, un burócrata con conocimientos técnicos específicos que los coloca a disposición de quien gobierna, ya que dichos conocimientos, según la visión tecnificista, son neutros, sin intencionalidades políticas, lo que ha sido cuestionado pero aún está vigente en el imaginario popular. De esta forma pueden servir a diferentes gobiernos, de orientaciones variadas, que no cuestionaban.

Igualmente, el mundo occidental y cristiano aprobaba soluciones autoritarias, con Estados Unidos, autoungido reino de la libertad, al frente (SMITH, 1996; SPOHR, 2012.) y la Iglesia católica como guardiana de las tradiciones por estas tierras, en un primer momento, con las que varios se identificaban, entre ellos nuestro protagonista.

Así, el Neoliberalismo y las dictaduras establecieron un nexo histórico mediante el que se apoyaron, aunque hay que mencionar la necesaria complejidad de todo proceso, al punto que las propias administraciones dictatoriales protegieron sus tecnócratas ortodoxos de los virulentos ataques de compañeros de armas que poseían un pensamiento diametralmente opuesto, en particular nacionalistas y desarrollistas. El conflicto en Brasil estuvo principalmente entre los proyectos encarnados por la linha-dura y la Sorbonne (RAMÍREZ, 2012), que podemos asemejar al que enfrentaron los partidarios de Videla y Díaz Bessone y Massera en Argentina y a Pinochet y Leigh en Chile.

Recordando los comentarios que hemos realizado sobre la Paradoja Ortodoxa, la simbiosis se daba también en el hecho de que los golpes de Estado, como constructos históricos y no meras coyunturas, compartían otro objetivo similar, el de alzarse como arietes contra aquellos que amenazasen el statu quo. De hecho, los golpes de Estado habían asumido carácter de contrarrevoluciones preventivas (SIDICARO, 1996), y las instituciones que propagaban el ideario 
neoliberal también operaban activamente con ese propósito, siendo verdaderos antídotos contra la rebelión (SMITH, 1996; y COCKETT, 1995), como bien reza el título del libro de Popper, La sociedad abierta y sus enemigos, epistemólogo que integró la exclusiva Mont Pelerin Society. El Neoliberalismo era mucho más que una teoría económica. Como hemos manifestado anteriormente, era la ideología asumida por el capitalismo para encarar su reformulación posfordista en su lucha contra el comunismo (PLEHWE; WALPEN; NEUNHÖFFER, 2006).

De hecho, un objetivo servía perfectamente al otro. La oposición que provocaría la reestructuración a nivel mundial en escala regional precisó imprimir un accionar represivo con el propósito de contrarrestar las voces disonantes que podrían levantarse, y que de hecho lo hicieron a pesar del nebuloso ambiente. No solo por parte de aquellos grupos que generalmente asociamos como antisistema, sino entre elementos de las propias fracciones burguesas.

Las dictaduras promovieron la mayor cantidad de reformas neoliberales de primera generación, sin las cuales tal vez la ola siguiente no se hubiera producido. En síntesis, desestructuraron el trípode sobre el cual se levantaba el modelo sustitutivo, que había entrado en crisis en los sesenta, y sentaron las bases de una nueva inserción internacional, básicamente promoviendo un brutal proceso de financierización de la economía, que provocó como efectos una mayor concentración, incluso intraburguesa, y un fuerte proceso de desindustrialización, apuntándose a una reprimarización de la base productiva, para lo cual se juzgaba que nuestros países tenían una vocación natural. Ello causó una gran mortandad de establecimientos, así como una fuerte concentración del ingreso, vía depresión del salario real, y hasta refriegas palaciegas de proyectos opuestos. Fue allí donde se quebró la resistencia de los sectores estatistas, dentro y fuera de sus aparatos, en particular del sector castrense, procediéndose al primer proceso de privatizaciones, generalmente periféricas, a pesar de lo cual el Estado salió endeudado por los abultados préstamos que se tomaron y por el descalabro fiscal que hubo, muchas veces para irrigar mediante obras faraónicas y promociones impositivas las arcas de determinadas empresas, que, recordemos, tampoco es una praxis ajena a los grupos neoliberales, aunque en apariencia esté reñida con su discurso libremercadista, del cual se disocian teoréticamente con abierto desempacho $\mathrm{u}$ otras intencionalidades.

De todas formas, hay que señalar que las dictaduras, y la de Brasil en particular, primera de todas matriciadas en ese cuño ${ }^{3}$, no se corresponden cronológicamente con las facciones que el Neoliberalismo asumió en su concepción más acabada de finales de los ochenta y principios de los noventa, por lo cual no podemos incurrir en ese anacronismo. En este sentido, algunas variantes que ayudaron a componerlo presentan características que después fueron soslayadas o solapadas en su síntesis final, y que están también presentes en las dictaduras, en especial la brasileña. De hecho, el programa económico de la dictadura y los principales nombres que asumen los puestos claves provienen del IPÊS, como lo enunciamos en 
un artículo donde ello se debate por extenso (RAMÍREZ, 2014).

En particular nos referimos a ciertas semejanzas con el Ordoliberalismo, por ejemplo, que de hecho fue formulado para el desarrollo alemán, en el cual la planificación está presente, algo que encaja muy bien en varios pasajes de la dictadura brasileña (KLEIN, 2013), constituyéndose en anatema posteriormente, y que también tuvo fuertes relaciones con la Doctrina Social de la Iglesia del periodo, al compartir no solo su propósito de combatir el comunismo de modo abstracto, sino también ideas respecto de la economía y varios métodos de cooptación de los trabajadores, por lo cual se conoce también como Economía Social de Mercado. Incluso, de hecho, Campos se auto intitula como "profeta", así como varios otros economistas hayan sido asociados a tal figura (MALABRE, 1994) y el Consenso de Washington fue elaborado bajo la forma de un decálogo.

Con esa breve mención pretendemos desterrar algunas ideas erróneas que tenemos acerca del Neoliberalismo. Por ejemplo, la de las ojerizas que tendría con algunas causas afines a sectores populares. La prédica del capitalismo salvaje no se condice, necesariamente con la prédica Neoliberal; en todo caso, no son tan necios al punto de matar la gallina que les da sus preciosos huevos de oro.

Tales enunciados aparecen claramente en Campos, especialmente en los capítulos sobre Reforma Agraria, Proyecto Social, Nuevo Laborismo, Poder Sindical Reconsiderado y Democratización del Acceso al Capital (2001, p. 685-724), con medidas que no le eran propias, sino que se habían debatido intensamente desde finales de 1961, principalmente por el IPÊS, integrado por empresarios, tecnócratas, políticos, militares y eclesiásticos, que fue uno de los principales articuladores del golpe de Estado de 1964 y proporcionó varios de sus cuadros al staff dictatorial. Soluciones que se anticipan en mucho a las propuestas del thatcherismo, que asumió en 1979.

De hecho, aún persisten varios interrogantes de las razones que llevaron a varios individuos y administraciones a suscribir ideas neoliberales. Pero de nuevo, la idea de una zona de desarrollo próximo es de gran utilidad; el Ordoliberalismo puede haber sido una excelente vía de ingreso, porque seguía senderos menos agresivos respecto a ideas preconcebidas que otras vertientes demonizaron vehementemente en etapas posterior (RAMÍREZ, 2007 y 2014; y BRISO, 2008), entre ellos el de dar cabida en el Estado a la planificación y promover un cierto entendimiento de clases. Ello no atraía solo a economistas provenientes del Estructuralismo, sino muy en especial a militares, que también habían abrevado en esas enseñanzas, a la par que se mostraban preocupados con esos asuntos por cuestiones de soberanía nacional, que aquellas otras posiciones barrerían al pregonar la globalización como panacea, orden en el que pasaban a estar subordinados.

Así, amparado en sus primeras incursiones por la teoría ortodoxa, su paso por la Iglesia católica y las necesidades de progresión en el selecto y resbaladizo escalafón burocrático, que osciló hacia el conservadurismo, Campos se despojó sin tapujos de su 
pasado más próximo al Keynesianismo y Estructuralismo para salir en defensa del orden vigente, abrazando soluciones cada vez más Ortodoxas.

De todos modos, si sus comentarios sobre dónde abrevó teóricamente durante su reconversión a la economía son escuetos, los que nos orientan sobre el proceso que lo llevó a abrazar el Neoliberalismo son casi nulos, contando solo con indicios. En este sentido, después de su paso por el Gobierno y breves experiencias como gestor, rumbeó de nuevo por la senda diplomática, que parecía ser su puerto seguro, para utilizar una metáfora marítima tan cara a Campos, siendo apostado en Londres como embajador, exactamente en momentos en los que se producía el ascenso de Margaret Thatcher al poder, que daría cuerpo a la gran ola neoliberal, proceso que parece haberlo marcado profundamente, a juzgar por el extenso capítulo que le destina a la experiencia, más de cien páginas (2001, p. 927-1033). Capítulo XVII, Missão Junto à Corte de Saint James), así como su calificación entre los grandes "hombres" que conoció (2001, p. 1053).

De todos modos esa identificación constituyó un refuerzo más que el disparador de su conversión. En ese sentido, el propio Roberto Campos es una muestra del modo en que el Neoliberalismo se difundió por sobre esa mortandad teórica, como discurso algo superficial, con poca sofisticación teórica, en el que su fuerza estuvo centrada particularmente en la articulación política y comunicativa, que justo por sus debilidades pudo ser inoculada como ideología de gran alcance (MAJONE, 1989.).
Si observamos detenidamente la profusa obra de Campos, por lo cual sus argumentos de timidez nos parecen inválidos, vemos que sus intencionalidades teóricas se registran en sus momentos iniciales, rehuyendo de ellas a medida que su ortodoxia aumenta, cuando pasa a dedicarse a propalar su buena nueva.

El pensamiento de Roberto Campos, en este sentido, parece seguir los derroteros de otras personalidades, que también se presentan, prima facie, como erráticos, pero que en realidad revelan las propias contradicciones del proceso histórico, en el que los actores fueron ubicándose en determinados momentos en posiciones que posteriormente podrían parecer incómodas. Perturbación que los llevaría a abandonarlas para recolocarse de nuevo en posiciones ventajosas. Las adhesiones teóricas se pueden dar por diversos motivos, el de compartirlas intelectualmente puede ser uno de ellos, pero también por otras causas, entre ellas la de ganar el sustento y ascender en la escala social, ya que muchas veces ella determina quién ingresa o no en determinados grupos, en los que se sumerge a través del Neoliberalismo, convirtiéndose en uno de sus difusores más encumbrados en Brasil.

\section{Conclusiones}

En síntesis, por cierto somos de la idea que las trayectorias de vidas individuales poseen componentes que les son peculiares; de todos modos, ellas no se alejan mucho de lo que su Zeitgeist les marca, no como imposición a rajatabla, sino más bien actuando como marcos en el que ellas pueden transi- 
tar, a veces con cierta libertad o autonomía, de acuerdo a las posibilidades que se les abren por su posición de origen y sus trayectorias pasadas.

El pensamiento de Roberto Campos fue del Estructuralismo moderado que era dominante en la década del cincuenta, cuando se forma e ingresa en la vida pública, al Neoliberalismo, que abraza por completo al punto de desdeñar sus anteriores posiciones, casi como una herejía de juventud, para ser más poéticos que sus propias palabras.

Tal deslizamiento no fue lineal, apreciación que en rigor le cabe a todo proceso histórico, aunque no sufrió paralizaciones prolongadas ni retrocesos, al menos fácilmente perceptibles en sus principales obras y acciones. De todos modos podemos encontrar una zona de inflexión muy clara a finales de los cincuenta y principios de los sesenta, con la crisis del sistema sustitutivo, inevitable en su cierne y concerniente al desarrollo capitalista regional, que habría de movilizar la burguesía, sus intelectuales y fuerzas de apoyo, burocráticas y militares, a nivel local y regional, para tratar de encontrar una salida, en particular cuando el proceso de radicalización les hizo temer por soluciones más drásticas aún.

A pesar de que en Brasil se intentó con ahínco una restructuración dentro de los marcos democráticos, a medida que los problemas se agudizaban, las posiciones también se radicalizaban, alejándose los defensores del statu quo del centro, en dirección a posiciones más rígidas. En contrapartida, incluso por equívocos de diagnóstico, aquellos que propugnaban reformas también dieron un giro, en sentido inverso. Así, los conten- dientes oscilaron hacia los extremos y tensionaron la coyuntura hasta un punto de no retorno. Es allí cuando percibimos que Roberto Campos produce su reconversión teórica, para colocarse en sintonía con los nuevos dictados, desprendiéndose de su rancio estructuralista para vestir el modelo neoliberal.

De todos modos, el germen debía estar presente para que ello se procesase de modo benigno, sin parecer una traición, para su grupo y en su campo, que, como se ha probado, ejerce una presión considerable sobre aquellos que lo habitan, que a veces torna casi imposible tales reconversiones, debido al alto costo que los individuos deben pagar por saltos muy abruptos, al abandonar a aquellos que les dieron cobijo y aliento, sin ser admitidos plenamente en el grupo de acogida, despertando desconfianzas de todo tipo, que en algunos casos ni el tiempo ayuda a disipar.

Por ello, la importancia de utilizar un concepto como el de zona de desarrollo próximo, que puede brindar el eslabón necesario para explicar la transición entre un campo teórico y otro, tornando menos abruptas esas metamorfosis. Es decir, no se abandona al anterior corpus de una sola vez, sino que se lo hace de modo paulatino. El sujeto no da saltos en el vacío, no se desprende de su bagaje ni de su entorno sin que haya ganado confianza dentro del nuevo ambiente, incursión exploratoria que le permitirá realizar posteriormente su translación definitiva.

Al tener en su maestría un director de tesis y profesores que comulgaban con posiciones ortodoxas, vía legitimación por autoridad, así como un padrino local de peso, el 
ideario neoliberal fue siendo adquirido por Campos de modo paulatino. Esta primera aproximación puede haber sido la vía de entrada dentro de la gran constelación que representa el Neoliberalismo; de lo contrario, pasar a comulgar con otras corrientes más alejadas del estructuralismo tal vez no hubiera sido posible.

No por nada, Roberto Campos declara su pasión madura por el pensamiento de Hayek, de la Escuela Austríaca, que también fue discípulo de Mises, como los profesores que destaca en sus memorias, que tuvo una trayectoria similar a estos, mucho más exitosa, ya que también buscó refugio en Estados Unidos, luego de abandonar Austria tras la ocupación alemana.

De este modo, universidades y think tanks han promovido en Estados Unidos un verdadero aluvión en sus cursos de posgrado, con lo cual realizan tal proceso en gran escala, claro que no siempre con total éxito, ya que invariablemente existen márgenes para comportamientos desviantes, pero, aplicando la ley de los grandes números, podemos inferir que le haya sido mayoritariamente positivo.

Además de la transformación operada en el campo intelectual hegemónico, el haber pertenecido a las huestes de la Iglesia católica, que por aquella época tenía valores cercanos a los que comulgaban los grupos que constituyeron en sus prolegómenos la ideología neoliberal, en especial la corriente ordoliberal, también debe haber colaborado para hacer ese tránsito factible, que se vio aún más refrendado por el estrecho círculo en el que consiguió penetrar dentro del Itamaraty y el mundo de las finanzas locales, que se distanciaron del Estructuralismo cuando sintieron amenazado el orden de dominación local, a la vez que debieron ajustarse a los nuevos designios a los cuales servían, como funcionarios públicos, menos libres que otros intelectuales.

De este modo, la trayectoria de Campos no puede ser vista como un ejemplo aislado, sino que nos ayuda a entender cómo en tan poco tiempo el campo de la economía transitó de una posición a otra, muy diferente en términos teóricos e ideológicos, cataclismo casi de escala geológica si se quiere, que alcanzaría varios rincones del planeta, provocando un cambio abrupto no solo en las opciones teóricas preferentes, sino también en las prácticas políticas adoptadas, entre las cuales estas visiones pasaron a predominar, primero de modo impositivo, ya sea por regímenes autoritarios que fueron instalados en la región, o por exigencia de órganos internacionales que así lo determinaban, y después hegemónicamente, es decir, sin el concurso de la fuerza, física o simbólica, a lo que Campos dedicó, con algunas intermitencias, cuarenta años de su vida, que superó diversas circunstancias históricas en mares agitados. 


\section{Abstract}

From the narrative of self, in this article, we investigate the turning experienced in thought and public action of Roberto Campos, key player of the Brazilian economic policy in the latter half of the last century, whose route ran from positions close to the Structuralism in his youth to embrace the orthodox variant of Neoliberalism later, made in activist mode. Explaining the reasons for this transmutation, we note that his trajectory was not only a single sample, but illustrating as special implications, the paths was followings in the region for the field of the economy in general, the public policy and other personalities in particular, also they keep on such a course and can be better understood in light of this.

Keywords: Brazil. Economical thought. Narrative of self. Political action. Roberto Campos.

\section{Resumo}

A partir da escrita de si, no presente artigo, indagamos sobre o giro experimentado no pensamento e na ação pública de Roberto Campos, figura chave da política econômica brasileira na última metade do século passado, percurso no qual se deslizou desde posições próximas ao Estruturalismo, na sua juventude, para abraçar a variante mais ortodoxa do Neoliberalismo, mais adiante, de modo militante. Ao explicar as razões dessa transmutação, observamos que sua trajetória não foi apenas uma amostra individual, mas ilustra, com seus ma- tizes particulares, os caminhos seguidos na região pelo campo da economia, de modo geral, pelo das políticas públicas e por outras personalidades em particular, que também traçaram curso semelhante e podem compreender-se melhor à luz da biografia.

Palavras-chave: Ação política. Brasil. Escrita de si. Roberto Campos. Pensamento econômico.

\section{Notas}

1 CAMPOS, R. de O. A lanterna na popa. Memórias. 2 volúmenes. Río de Janeiro: Editora Topbooks, 2001, p. 20. En adelante para esta obra sólo se indica el número de página,

2 En una reunión del Instituto de Pesquisas e Estudos Sociais (IPÊS), al que había pertenecido Roberto Campos y que tuvo gran protagonismo en el golpe de Estado de 1964, Glycon de Paiva Teixeira opinó que dicho Instituto debía convertirse en un centro de "'post-graduation' [...] [para] economistas, visando neutralizar os cepalistas, todos mais ou menos 'tisnados'". Subrayado en el original. Acta de la Reunión Plenaria del Comité Ejecutivo del IPÊS, 8/4/63.

3 Las dictaduras argentinas son más antiguas, mas, la historiografía divide ellas a partir de la instaurada en 1966, cuando el aspecto represivo se acentúa así como su duración.

\section{Referências}

BALSA, J. Hegemonías, sujetos y revolución pasiva. Tareas, [s.n.], n. 125, p. 18-32, 2007.

BIELSCHOWSKY, R. A. Pensamento econômico brasileiro: o ciclo ideológico do desenvolvimentismo. Rio de Janeiro: Contraponto, 1995.

BRISO, J. L. P. N. O conservadorismo em construção: o Instituto de Pesquisas e Estudos Sociais (IPES) e as reformas financeiras da Ditadura Militar (1961-1966). 2008. 203 f. Dissertação 
(Mestrado em História Econômica) - Universidade Estadual de Campinas, Campinas, 2008.

CAMPOS, R. de O. A lanterna na popa: memórias. 2 v. Rio de Janeiro: Topbooks, 2001.

COATS, A. W. Economists in international agencies. Nueva York: Praeger, 1986.

CORBALÁN, M. A. El Banco Mundial: intervención y disciplinamiento (el caso argentino, enseñanzas para América Latina). Buenos Aires: Biblos, 2002.

EVANS, P. B. The state as problem and solution: predation, embedded autonomy and structural change. In: HAGGAR, S.; KAUFMAN, R. (Ed.). The politics of economic adjustment. Princeton: Princeton University Press, 1992.

GARRETÓN, M. A. Proyecto, trayectoria y fracaso en las dictaduras del Cono Sur (un balance). Alternativas, Santiago, n. 2, p. 2-34, 1984.

HAMMERSLEY, M. The politics of social research. Londres: Sage Publications, 1994.

HARVEY, D. O neoliberalismo: história e implicações. São Paulo: Loyola, 2008.

HOFSTADTER, D. R.; DENNETT, D. C. (Ed.). El ojo de la mente: fantasías y reflexiones sobre el yo y el alma. Buenos Aires: Editorial Sudamericana, 1981-1983.

KAHLER, M. Orthodoxy and its alternatives: Explaining approaches to stabilization and adjustment. In: NELSON, J. M. (Ed.). Economic crisis and policy choice. Princeton: Princeton University Press, 1989.

KLEIN, C. R. de M. Roberto Campos e o Ordoliberalismo alemão: ideias e planejamento para o Brasil (1963-1987). 2013. 148 f. Dissertação (Mestrado em História) - Universidade do Vale do Rio dos Sinos, São Leopoldo, 2013.

LINZ, J. Una interpretación de los regímenes autoritarios. Papers - Revista de Sociología, Barcelona, n. 8, p. 64-88, 1978.
MAJONE, G. Evidence, argument and persuasion in the policy process. Nueva Haven: Yale University Press, 1989.

MALABRE, A. L. Lost prophets: an insider's history of the modern economists. Boston: Harvard Business School Press, 1994.

OVERBEEK, H. (Ed.) Restructuring hegemony in the global political economy: the rise of transnational neo-liberalism in the 1980s. Londres: Routledge, 1993.

PLEHWE, D. A global knowledge bank? The World Bank and bottom-up efforts to reinforce neoliberal development perspectives in the post-Washington consensus era. Globalizations, Estados Unidos, v. 4, n. 4, p. 32-45, 2007.

. Transnational discourse coalitions and monetary policy: Argentina and the limited powers of the "Washington Consensus". Critical Policy Studies, Estados Unidos, v. 5, n. 2, p. 55-65, 2011.

PLEHWE, D.; WALPEN, B.; NEUNHÖFFER, G. (Ed.). Neoliberal Hegemony: a global critique. Londres: Routledge, 2006.

RAMÍREZ, H. A configuração das alianças golpistas nas ditaduras de Brasil e Argentina: uma perspectiva a partir da imbricação cívico-militar. Estudos Ibero-Americanos, Porto Alegre, v. 38, n. 1, p. 155-178, 2012.

. Corporaciones en el poder, institutos económicos y acción política en Brasil y Argentina: IPÊS, FIEL y Fundación Mediterránea. Buenos Aires: Lenguaje Claro, 2007.

. La dictadura brasileña como proyecto refundacional, una perspectiva desde las propuestas ipesianas. Diálogos, Maringá, v. 18, n. 1, p. 93-113, 2014.

. O neoliberalismo sul-americano em clave transnacional: enraizamento, apogeu e crise. São Leopoldo: Edunisinos/Oikos, 2013.

- Reflexiones acerca de las Dictaduras del Cono Sur como proyectos refundacionales. Antíteses, Londrina, v. 8, n. 2, p. 132-159, 2015. 
SIDICARO, R. El régimen autoritario de 1976: refundación frustrada y contrarrevolución exitosa. In: TCACH, C.; QUIROGA, H. (Coord.). A veinte años del golpe: con memoria democrática. Rosario: Homo Sapiens, 1996.

SKLAR, H. Trilateralism, the Trilateral Commission and elite planning for world management. Boston: South End Press, 1980.

SMITH, J. A. The idea brokers: think tanks and the rise of the new policy elite. Nueva York: The Free Press, 1991.

SMITH, P. H. Talons of the eagle: dynamics of U.S.-Latin American relations. Nueva York: Oxford University Press, 1996.

SPOHR, M. O empresariado e as relações Brasil-Estados Unidos no caminho do golpe de 1964. Confluenze, Bologna, v. 4, n. 2, p. 45-62, 2012. 